\title{
Postischemic Liver Damage in Rats: Amino Acid Analysis and Morphometric Studies
}

\author{
Hidemi Yamauchi,* Ulrich Mittmann, $\dagger$ Hans Peter \\ Geisen $\dagger$ and Manfred Salzer + \\ * The First Department of Surgery, Tohoku University School \\ of Medicine, Sendai 980, and $\dagger$ Department of Surgery and \\ $\ddagger$ Department of Biochemistry, University of Heidelberg, \\ West Germany
}

\begin{abstract}
Yamauchi, H., Mittmann, U., Geisen, H.P. and Salzer, M. Postischemic Liver Damage in Rats: Amino Acid Analysis and Morphometric Studies. Tohoku J. exp. Med., 1982, 138 (1), 49-61 — Normothermic, temporary, total ischemia of the liver was produced for 60-225 min under transient portal decompression with a by-pass between the mesenteric and the femoral vein. Total amino acids in the liver tended to increase after an ischemic period of more than $120 \mathrm{~min}$ without reperfusion as compared with control with increasing trends in most of the individual amino acids. In a group undergoing $120 \mathrm{~min}$ of ischemia and $60 \mathrm{~min}$ of reperfusion, total amino acids and individual amino acids tended to decrease. Total plasma amino acids significantly increased after ischemia of more than $120 \mathrm{~min}$. Without reperfusion, elevations of almost all amino acids except for branched chain amino acids were found, whereas after reperfusion most of the individual amino acids also increased including branched chain amino acids. Molar ratios of branched chain amino acids to tyrosine and phenylalanine decreased only after more than $120 \mathrm{~min}$ ischemia without reperfusion. Volume ratios of organelle disintegration on electron micrographs such as mitochondrial degradation and autophagic vacuoles were moderately increased after $90 \mathrm{~min}$ ischemia with a further steep rise after more than $120 \mathrm{~min}$ ischemia. The survival rates of the animals after 60,90 and $120 \mathrm{~min}$ ischemia were $35 \%$ $(6 / 17), 27 \%(3 / 11)$ and $25 \%(3 / 12)$, respectively. The following conclusions were obtained: 1) Pre-necrosis of the hepatocytes with simultaneous protein degradation started after ischemia for about $2 \mathrm{hr}$. The survival rates of the animals after 60 and $90 \mathrm{~min}$ ischemia were very low despite of mild necrosis of the liver. 2) Most of the amino acids in the liver were washed out into the plasma to cause an abnormal plasma amino acid pattern in the acute state. However, the molar ratio of branched chain amino acids to aromatic group was not reduced, in contrast to the ischemic group without reperfusion. - ischemic liver damage; morphometry; amino acid
\end{abstract}

Although ischemic liver damage is a major subject in liver surgery and a relatively large number of investigations are available, the precise process from

Received for publication, December 28, 1981.

* Fellow of Alexander von Humboldt Foundation, 1979-1981.

This work is supported by Alexander von Humboldt Foundation, Bonn, West Germany and Department of Surgery, University of Heidelberg, West Germany (Director, Prof. Fritz Linder), and was presented at the 29th Congress of Société Internationale de Chirurgie, Montreux, Switzerland, 1981. 
the start of cellular death to distinct necrosis after ischemia, in particular in relation to the animal death, lacks in clarity.

The first aim of this paper is designed to determine the point of irreversibility of hepatocyte damage after ischemia and to evaluate the correlation between hepatocellular and animal death. On the other hand, a great deal of attention has been paid to the abnormal molar ratio of branched chain to aromatic amino acids in the plasma as a major implication in hepatic encephalopathy. Little is known, however, about the source of the abnormal amino acids that induce lowering of the molar ratio, especially those of aromatic amino acids, and it is the second aim of this paper to assess the cause of abnormal amino acid patterns in the plasma after hepatic ischemia.

\section{Materials and Methods}

Male Wistar strain rats weighing $280-370 \mathrm{~g}$ were subjected to the experiments after overnight fasting for $18 \mathrm{hr}$. Water was allowed ad libitum. A normothermic, temporary, total ischemia was produced on laparotomy by occluding the portal vein and the hepatic artery together with the common bile duct by means of a silk under ether anesthesia. All the animals received portal decompression through a transient by-pass between the mesenteric and femoral veins by the use of a 20 gauge cannule with a polyethylene tube.

The acute ischemic models were divided into 5 groups. Sixty, 90 and $120 \mathrm{~min}$ ischemia with further $1 \mathrm{hr}$ reperfusion were made in Groups 1,2 and 3, respectively. Reperfusion of the liver was performed by cutting the silk. The rats in Groups 4 and 5 underwent $60-90$ and $120-225 \mathrm{~min}$ ischemia with no further revascularization. Attempts were made to ligate all collateral vessels between the liver and other organs. A small arterial collateral was found to exist mostly between the left hepatic artery and the cardia. Before the ischemic procedure $1 \mathrm{mg} / \mathrm{kg}$ heparin-sodium was injected. Arterial blood pressure was monitored by way of the femoral artery except for chronic models, while portal pressure was measured with a water manometer intervening in the by-pass tube. During experiments $1 \mathrm{ml}$ of saline solution was injected every $30 \mathrm{~min}$, while glucose $(0.5$ $\mathrm{ml})$ and saline $(0.5 \mathrm{ml})$ were given for the chronic experiments of 120 min ischemia. Control animals were sham operated under anesthesia for a period of 1 to $3 \mathrm{hr}$. All surgical procedures were performed under sterile condition.

Animals were sacrificed by removing the blood from the abdominal aorta via the femoral artery before and/or $\mathbf{l} \mathrm{hr}$ after reperfusion in acute ischemic models. Liver biopsy for both optical and electron microscopic specimens was made at the same time.

Chronic ischemic models were also produced to estimate the necrotic fraction in an optical microscope and survival rates. For the estimation of necrotic fraction, histologic sections were obtained by liver biopsy $(n=11)$ or at the time of postmortem anatomy $(n=9)$ at $12-48 \mathrm{hr}$ after ischemia. The constant area of the left hepatic lobes were used for the morphometric estimation of the necrotic fraction. The left lobes were cut along the long axis and fixed in $10 \%$ formalin followed by hematoxylin and eosin staining. The $2 \mathrm{~cm}$ long hepatic specimens from the edge were used for the morphometry. Tissues for electron microscopy were fixed in $1 \%$ osmium tetroxide in 0.1 mole cacodylate buffer or by double fixation in $3 \%$ glutaraldehyde and $1 \%$ osmium tetroxide. They were dehydrated in a graded ethanol series and embedded in Epon-araldite mixture. After ultrathin sectioning with an ultramicrotome and double stainings with uranyl acetate and lead solution they were examined with an electron microscope, Zeiss EM $9 \mathrm{~S}-2$ at $60 \mathrm{kV}$.

Morphometric parameters such as mitochondrial volume fraction $(\mathrm{Vvm})$, ratio of surface of inner mitochondrial membranes including cristae to mitochondrial volume ( $\mathrm{sm} / \mathrm{vm})$, volume fraction of necrosis in an optical microscope $\left(\mathrm{Vvn}_{\mathrm{vn}}\right.$, and volume fraction of organelle 
disintegration ( $\mathrm{Vvd}$ ) were estimated by means of the point counting method (Weibel and Elias 1967; Yamauchi et al. 1976).

Immediately after the sacrifice of animals, the whole liver was perfused with a cardioplegia solution* by drip through the portal vein at a pressure of $20 \mathrm{~cm} \mathrm{H}_{2} \mathrm{O}$ for 5 min to exclude the blood from the liver. About $2 \mathrm{~g}$ of the liver tissue were stored at $-20^{\circ}$. Amino acid analysis was made as follows (Merz 1974; Müller et al. 1979; Just et al. in press): A piece of hepatic tissue was broken into powder manually with liquid air. Thereafter, $3 \mathrm{ml}$ of $\mathrm{HClO}_{4}, 2.5 \mathrm{~N}$, was added together with 200 nmoles norleucine per $\mathrm{g}$ of the liver tissue as an internal standard, then the tissue was homogenized and centrifuged for $10 \mathrm{~min}$ at $4,000 \mathrm{rpm}$. The supernatant was adjusted to $\mathrm{pH} 7.5$ and filtrated through a membrane, DIAFLO ultrafilter $(\mathrm{UM}-2) \dagger$. After evaporization, the sample was diluted with lithium buffer ( $\mathrm{pH}$ 2.2) and analyzed by a column chromatographic technique using an amino acid analyser (Biotronik, West Germany). For the estimation of plasma amino acids, $0.8 \mathrm{ml}$ of plasma was deproteinized by $120 \mu \mathrm{l}, 2.5 \mathrm{~N} \mathrm{HClO}_{4}$ and 100 nmoles norleucine was added to it. The other techniques were followed in the same way as in the liver analysis.

\section{ReSUlts}

Serum enzyme levels. As shown in Figs. 1, 2 and 3, the levels of S-GOT, S-GPT and $\mathrm{LDH}$ showed a remarkable rise after 60,90 and $120 \mathrm{~min}$ ischemia followed by $60 \mathrm{~min}$ reperfusion. Significant exponential correlations between these enzyme levels and ischemic periods were demonstrated. Moreover, the levels after $120 \mathrm{~min}$ ischemia showed a significant $(p<0.01)$ sharp rise as compared with those after $90 \mathrm{~min}$ ischemia. None of the enzyme levels, however, showed significant elevations in the plasma, when the ischemic livers had no further reperfusion.

Blood sugar. The blood glucose levels were declined correspondingly to the ischemic time. The means and standard deviations in control, and after 60, 90 and $120 \mathrm{~min}$ ischemia were $173 \pm 41 \mathrm{mg} / 100 \mathrm{ml}(n=5), 140 \pm 61(n=6), 83 \pm 23(n=$ 4 ) and $51 \pm 21(n=6)$, respectively. As a relatively large fall was noted in the 120 min group, glucose was given during ischemia of $120 \mathrm{~min}$ in chronic experiments.

Arterial pressure and portal vein pressure. The systemic arterial pressure before ischemia $(111 \pm 16 \mathrm{mmHg}, n=18)$ was found to be decreased by $24 \pm 15 \%$ after ischemia. A sudden drop in arterial pressure $(50-70 \mathrm{mmHg})$ was mostly noticed for about $15 \mathrm{~min}$ after the relief of ischemia, but the pressure recovered to the preischemic level by $1 \mathrm{hr}$ after reperfusion. The level of portal vein pressure $\left(145 \pm 23 \mathrm{mmH}_{2} \mathrm{O}, n=15\right)$ increased by $40 \pm 23 \%$ after $60 \mathrm{~min}$ ischemia. After reperfusion, the elevated portal pressure returned to the preischemic level.

Changes in hepatic weight. The ratio of hepatic weight to total body weight in control animals $(3.5 \pm 0.8 \%, n=4)$ remained unchanged after an ischemic procedure and perfusion with cardioplegia solution. The ratios after 60 to 90 min ischemia without and after reperfusion were $3.4 \pm 0.6(n=6)$ and $3.3 \pm 0.6(n=$ 14). Those after ischemia for more than $120 \mathrm{~min}$ without or after reperfusion

* $\mathrm{NaCl}(15 \mathrm{mVal} \mathrm{Na}+), \mathrm{KCl}\left(10 \mathrm{mVal} \mathrm{K}{ }^{+}\right), \mathrm{MgCl}_{2}\left(2.0 \mathrm{mVal} \mathrm{Mg2}{ }^{+}\right), 245$ mmoles mannit per $1,000 \mathrm{ml}$.

$\dagger$ Trade name of Amicon, Ltd., Lexington, Massachusetts, USA. 


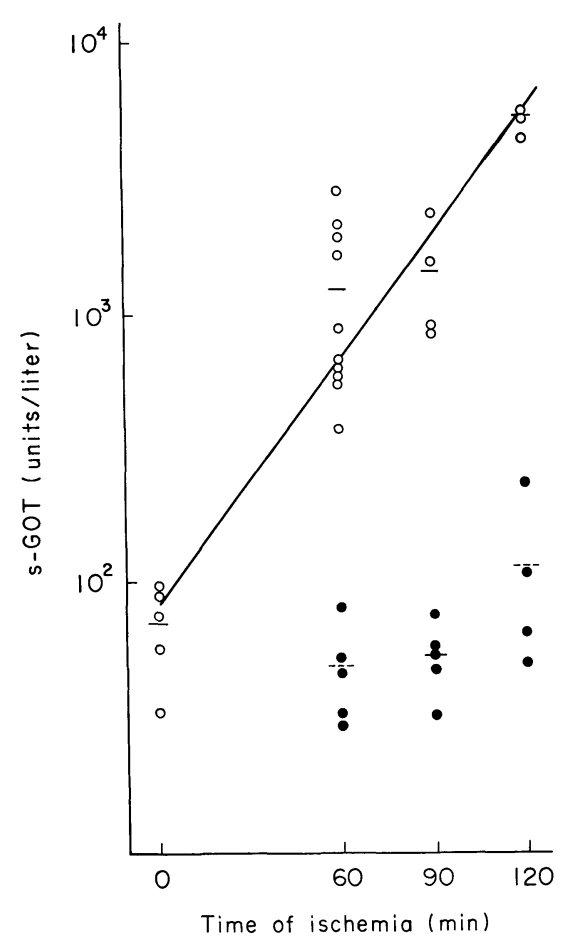

Fig. 1

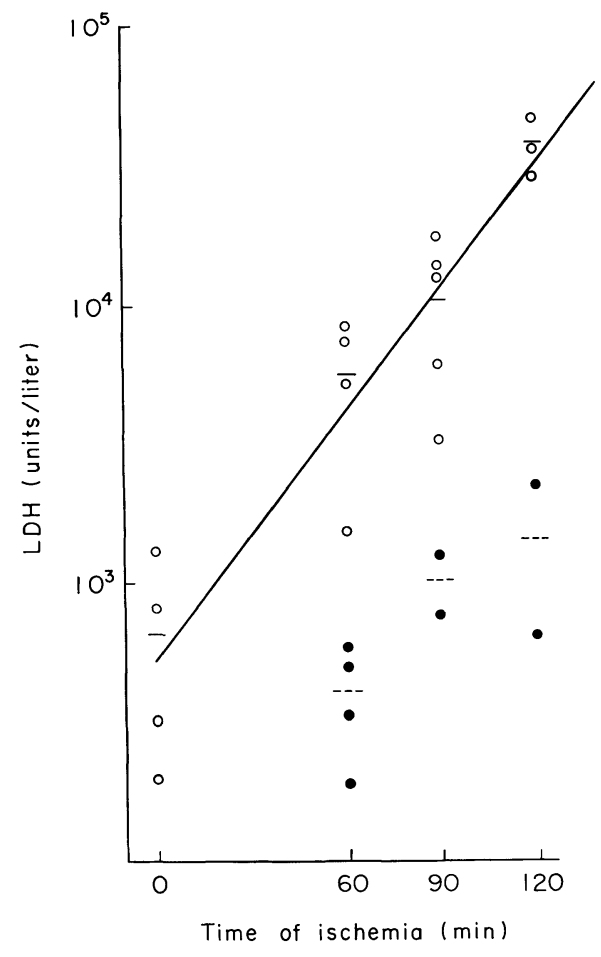

Fig. 3

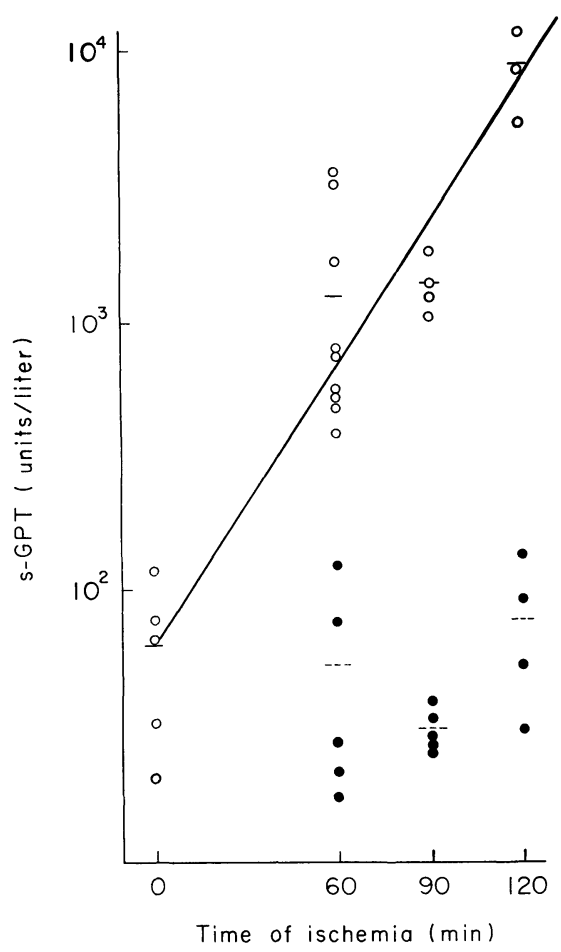

Fig. 2

Figs. 1, 2 and 3. Levels of S-GOT, S-GPT and $\mathrm{LDH}$ after ischemia. Significant exponential correlations between the enzyme levels and ischemic time are illustrated after reperfusion. Furthermore, significant steep rises after $120 \mathrm{~min}$ of ischemia are demonstrated. Without reperfusion, no significant increases are presented. ○, after reperfusion; •, without reperfusion. 
were $3.2 \pm 0.4 \quad(n=4)$ and $3.3 \pm 0.4 \quad(n=3)$. The possible growing edema during ischemia might be excluded.

Morphologic findings and morphometric measurements. The results are shown in Figs. 4-9 and Table 1. No necrotic hepatocytes were observed at $60 \mathrm{~min}$ of reperfusion after ischemia. Small necrotic densities as much as about $10 \%$ was found after 60 to 90 min ischemia followed by 12-48 hr reperfusion, while after $120 \mathrm{~min}$ ischemia necrotic fraction of about $50 \%$ were estimated.

The drastic changes after ischemia were demonstrated characteristically on the mitochondria. A marked enlargement of the mitochondria with an abnormal distribution of the cristae was presented (Fig. 4). After $120 \mathrm{~min}$ ischemia the mitochondria were accompanied by distinct vesiculation of the cristae (Fig. 5) or a loss of cristae and low density of the matrix (Fig. 6). These findings were well presented also in the morphometric parameters such as Vvm and sm/vm (Table 1).

In addition to the mitochondrial degradation, increased autophagic vacuoles were found (Fig. 7). Fig. 8 illustrate the fraction of the autophagic vacuoles and mitochondrial degradation, which was defined as organelle disintegration ( $\mathrm{Vvd})$ in the present investigation. A significant steep rise in $\mathrm{Vvd}$ was noticed in the liver after $120 \mathrm{~min}$ ischemia followed by $60 \mathrm{~min}$ reperfusion (Fig. 8 left). A similar sharp increase in $\mathrm{Vvd}$ was demonstrated in the liver after ischemia for more than 120 min with no further revascularization (Fig. 8 right).

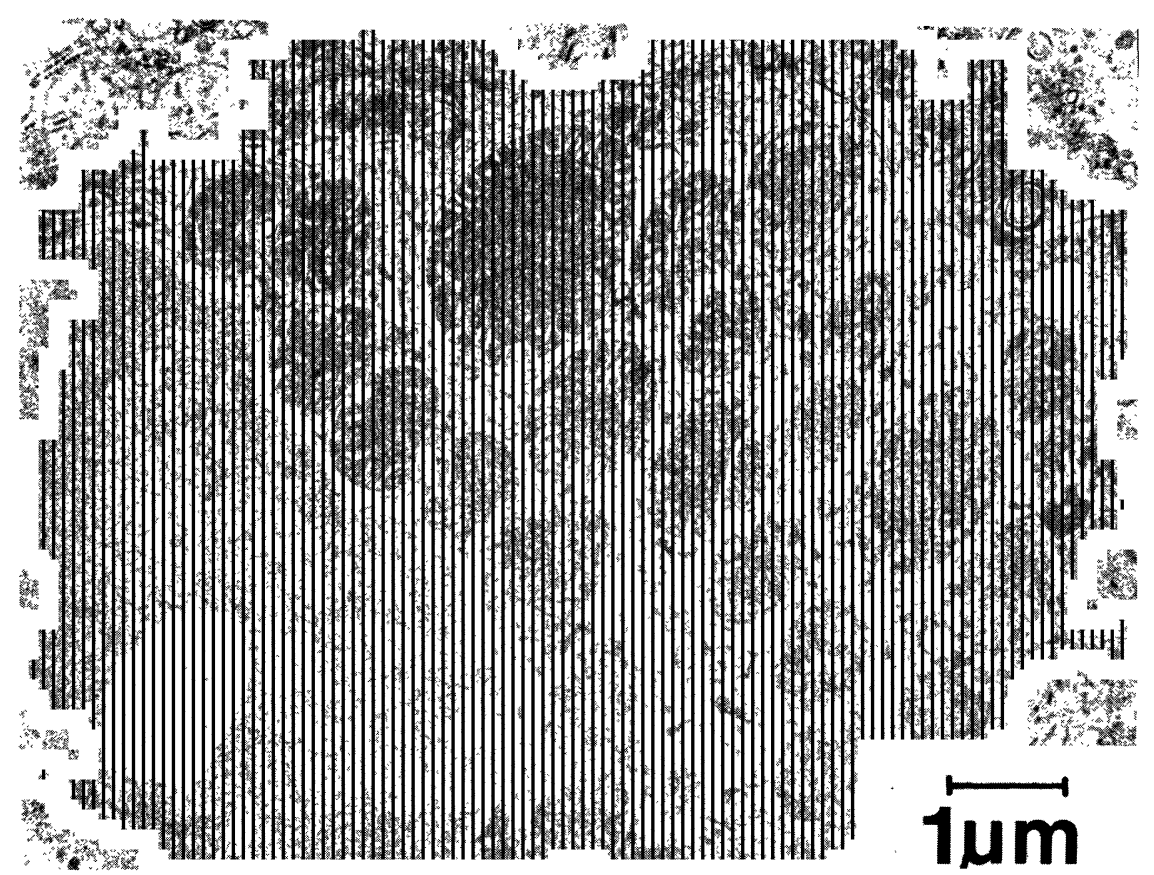

Fig. 4. After 60-90 min of ische mia and $60 \mathrm{~min}$ of reperfusion, mitochondria showed marked dilatation with abnormal distribution of the cristae. 
N. Yamauchi et al.
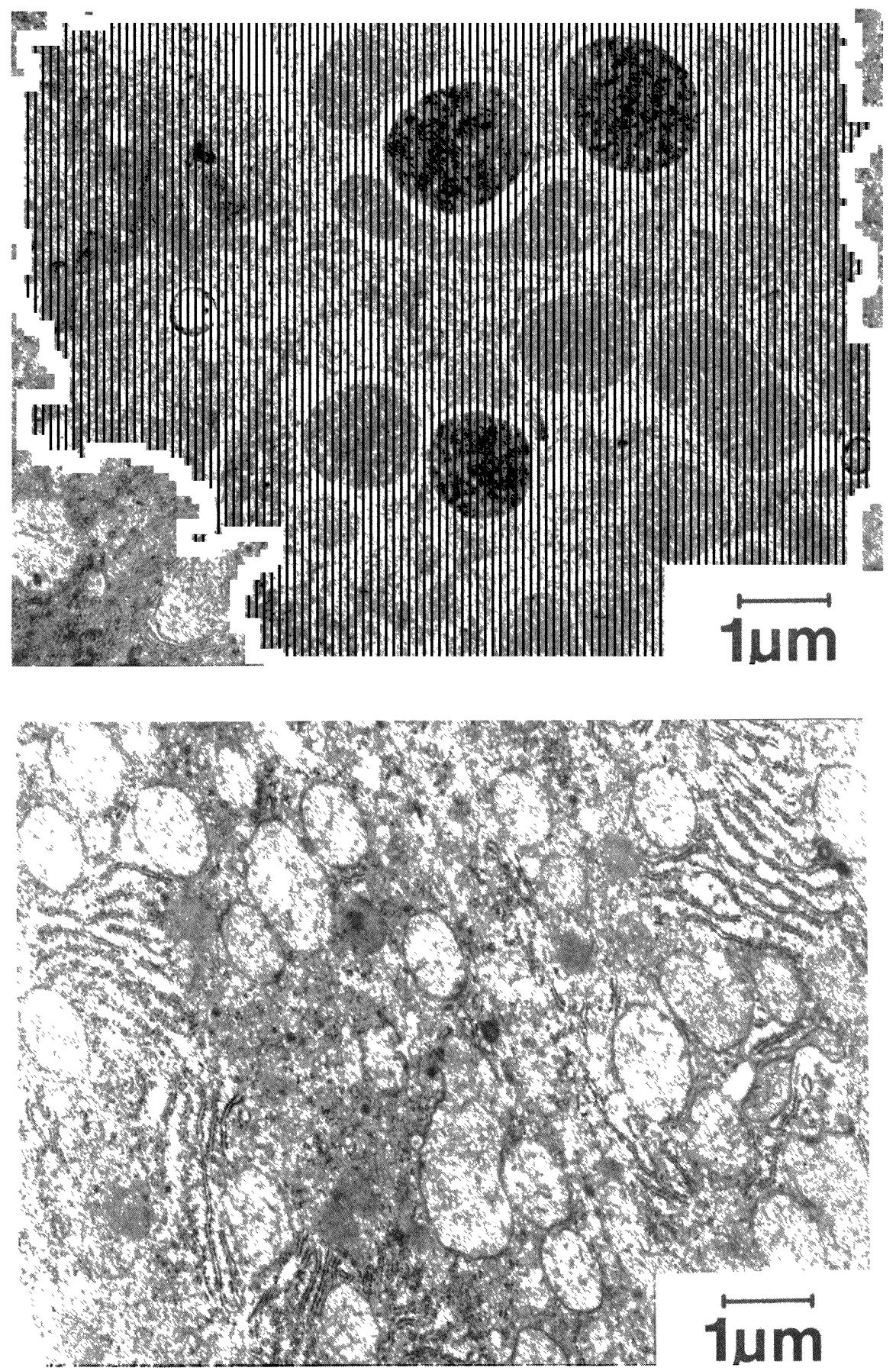

Figs. 5 and 6. After $120 \mathrm{~min}$ of ischemia some mitochondria indicated loss of cristae membrane with lucent matrix (Fig. 5) or vesiculation of the cristae membranes (Fig. 6). 
TABLE 1. Morphometric parameters

\begin{tabular}{|c|c|c|c|c|}
\hline \multirow[t]{2}{*}{ 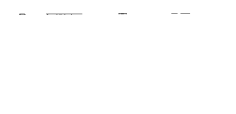 } & \multirow{2}{*}{ Control } & \multicolumn{3}{|c|}{ Ischemia } \\
\hline & & $60 \mathrm{~min}$ & $90 \mathrm{~min}$ & $120 \mathrm{~min}$ \\
\hline $\operatorname{Vvm}(\%)$ & $18.4 \pm 2.4(n=7)$ & $36.2 \pm 6.1(n=6)$ & $37.6 \pm 7.5(n=6)$ & $32.2 \pm 11.6(n=5)$ \\
\hline $\mathrm{sm} / \mathrm{vm}\left(\mathrm{m}^{2} / \mathrm{cm}^{3}\right)$ & $20.3 \pm 5.9(n=7)$ & $12.7 \pm 1.7(n=6)$ & $9.2 \pm 1.6(n=6)$ & $10.0 \pm 3.2(n=5)$ \\
\hline $\operatorname{Vvn}(\%)$ & & $\begin{array}{r}10.0(0-26.4) \\
(n=7)\end{array}$ & $\begin{array}{r}11.0(0-29.5) \\
(n=8)\end{array}$ & $\begin{array}{r}46.0(10.7-100) \\
(n=5)\end{array}$ \\
\hline
\end{tabular}

Vvm, volume ratio of the mitochondria to the cytoplasm excluding the nucleus; $\mathrm{sm} / \mathrm{vm}$, inner mitochondrial membranes with cristae to mitochondrial volume; Vvn, necrotic fraction of the liver in optical microscope.

Values are the mean \pm s.D. or mean (range).

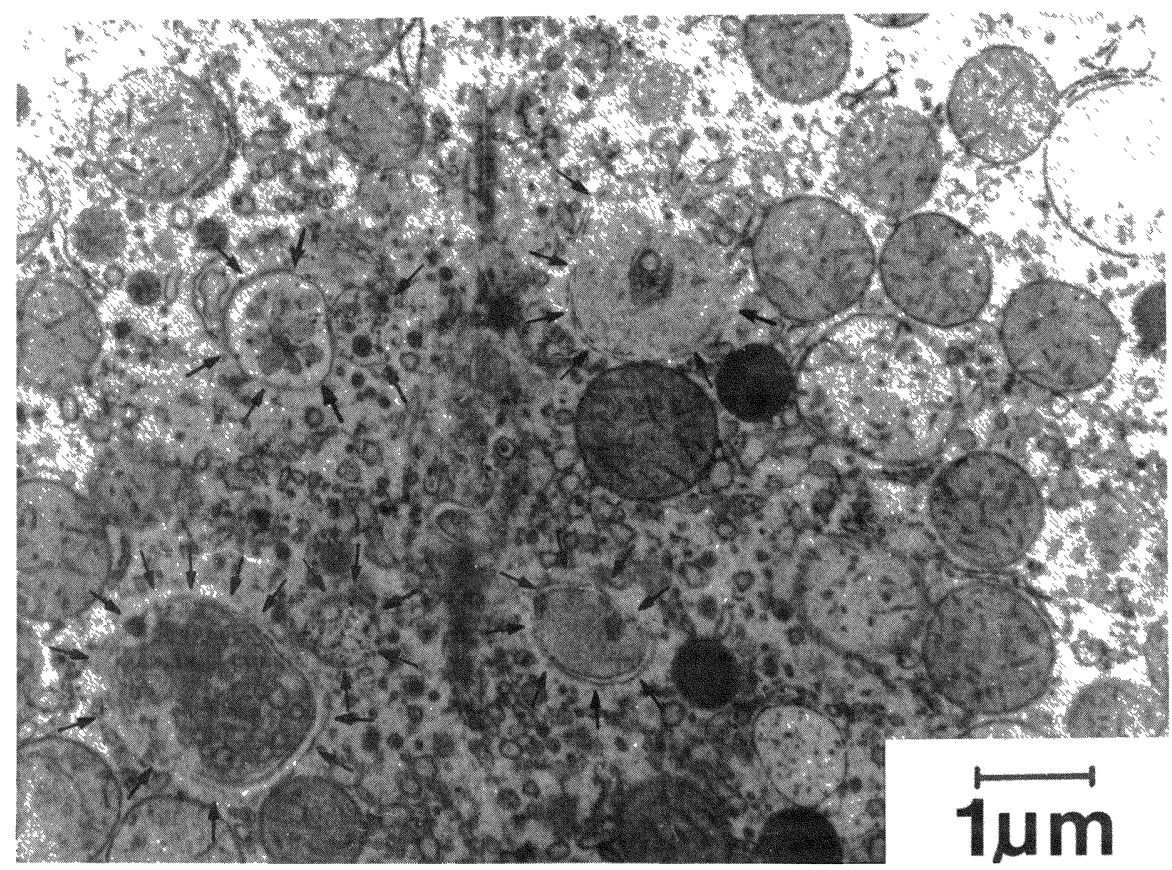

Fig. 7. A remarkable increase in autophagic vacuoles with various steps (arrows) was presented in the liver of $180 \mathrm{~min}$ of ischemia without reperfusion.

Amino acid analysis. The values of amino acids in the liver and the plasma are listed in Tables 2 and 3 together with the amounts of total amino acids, taurine and ammonia, and the molar ratios. Total amino acids were calculated by totalizing all the individual amino acids except for citrulline and ornithine. The total amino acids tended to increase in the livers after ischemia for more than 120 225 min (Group 5) with a significant increase in aspartate + asparagine, threonine, serine and ornithine, and an increasing trend in glutamine+glutamate, alanine, glysine, methionine and lysine. A significant correlation between total amino acids and ischemic periods is illustrated in Fig. 9. On the contrary, the values of 
total amino acids in the liver after $120 \mathrm{~min}$ ischemia and $60 \mathrm{~min}$ reperfusion (Group 3) tended to decrease. Most of the amino acids decreased including branched chain and aromatic amino acids except for asparagine+aspartate, serine and ornithine.

On the other hand, there was a significant increase in total amino acids in the plasma in Groups 2, 3, 4 and 5. The regression equations between total amino acids and ischemic periods in control, and Groups 1,2 and 3 are $Y=3.8 \cdot e^{0.0078 X}$, $r=0.63, p<0.01$, while those in control, and Groups 4 and 5 are $Y=4.5 \cdot e^{0.0077 X}$, $r=0.75, p<0.01$.
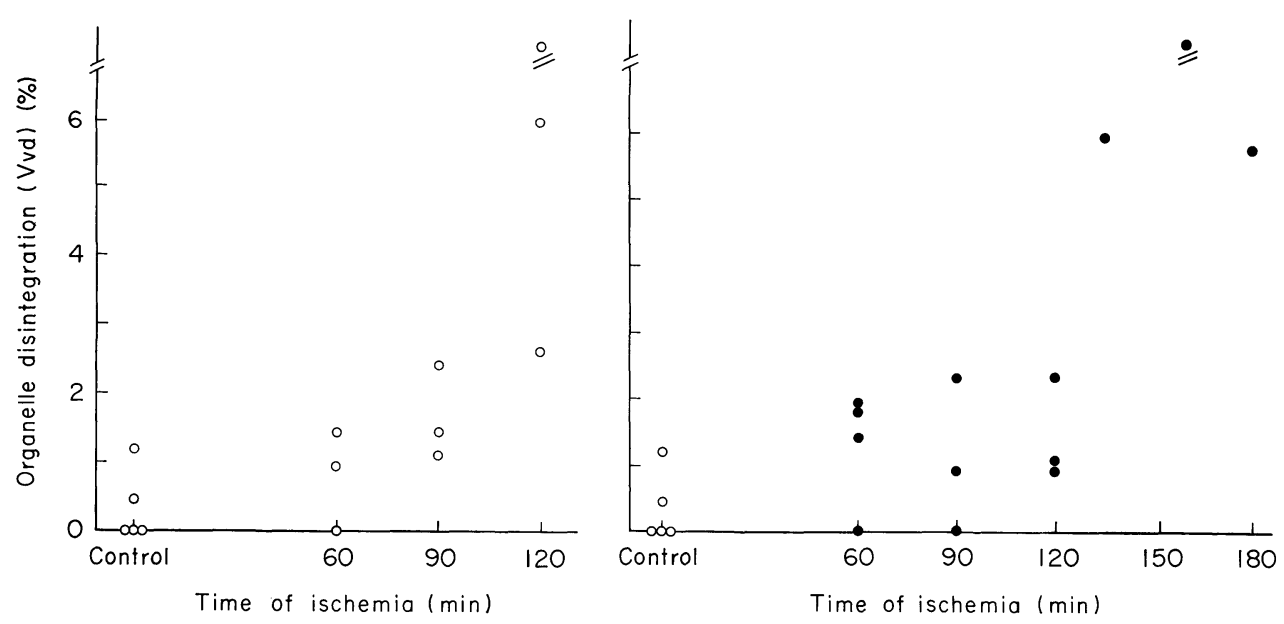

Fig. 8. Organelle disintegration ( $\mathrm{Vvd}$ ) (volume fraction of mitochondrial degradation plus autophagic vacuoles) was increased after reperfusion (left). The significance levels are 0.1 at $90 \mathrm{~min}$ of ischemia and $60 \mathrm{~min}$ of reperfusion, and 0.05 at $120 \mathrm{~min}$ of ischemia and $60 \mathrm{~min}$ of reperfusion. Without reperfusion a significantly increased $\operatorname{Vvd}(p<0.001)$ was noted after ischemia for more than $120 \mathrm{~min}$, with an increasing trend in $90 \mathrm{~min}$ ischemia (right).

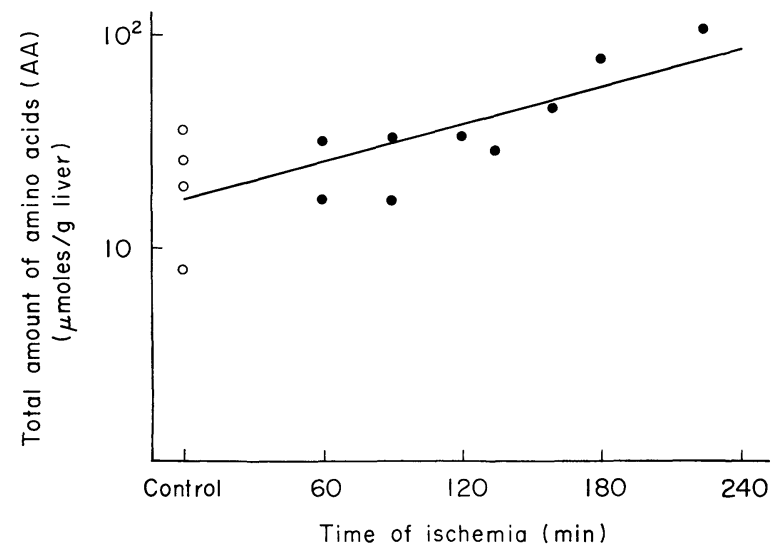

Fig. 9. Total amount of amino acids in the liver after ischemia without reperfusion. A significant correlation between total amino acids and ischemic time is illustrated. $Y=16.7 \cdot e^{0.0067 X}, r=0.76, p<0.01$. 
TABLE 2. Amino acid analysis in the plasma

\begin{tabular}{|c|c|c|c|c|c|c|}
\hline & $\begin{array}{c}\text { Control } \\
n=5\end{array}$ & $\underset{n=4}{\text { Group }} 1$ & $\underset{n=6}{\text { Group }} 2$ & $\begin{array}{c}\text { Group } 3 \\
n=4\end{array}$ & $\begin{array}{c}\text { Group } 4 \\
n=5\end{array}$ & $\begin{array}{c}\text { Group } 5 \\
n=4\end{array}$ \\
\hline Taurine & $0.69(0.71)$ & $1.22(2.08)$ & $1.42(1.03)^{\mathrm{c}}$ & $2.21(1.45)^{\mathrm{c}}$ & $1.66(2.03)^{\mathrm{b}}$ & $1.79(2.12)^{b}$ \\
\hline $\begin{array}{l}\text { Aspartatef } \\
\text { Asparagine }\end{array}$ & 3) & $0.09(0.2$ & $0.26(0.66)$ & $0.02(0.07)$ & & \\
\hline Threonine & $25(0.39)$ & $.29(0.50)$ & $0.45(0.73)$ & $0.39(0.62)$ & $0.55(1.05)$ & $0.76(1.33)^{\mathrm{a}}$ \\
\hline & & 6) & 321 & $0.10(0$. & & \\
\hline $\begin{array}{c}\text { Glutamate+ } \\
\text { Glutamine }\end{array}$ & & $0.91(2.41)$ & $0.95(1.68)$ & $1.66(0.38)^{\mathrm{b}}$ & & $1.63(1.30)^{\mathrm{c}}$ \\
\hline Glycine & & $69(0.83)$ & $1.05(2.20)$ & $2.43(1.70)^{\mathrm{C}}$ & $1.74(1.74)^{\mathrm{C}}$ & $2.18(1.93)^{\mathrm{c}}$ \\
\hline & & & $45)^{\mathrm{b}}$ & $2.75(1.42)^{\mathrm{c}}$ & & $52)^{c}$ \\
\hline Valine & & $39(0$ & 0.44( & $0.64(0.50)^{\mathrm{b}}$ & & \\
\hline Methionine & & $.08(0.14)$ & 0.16( & $0.26(0.20)^{\mathrm{c}}$ & 0.1 & $.37)^{b}$ \\
\hline Isole & $(0.18)$ & $0.09(0.16)$ & $0.21(0.27)$ & $0.21(0.13)^{\mathrm{a}}$ & 0.18 & $(0.40)$ \\
\hline Leucine & $0.23)$ & $0.24(0.32)$ & $0.46(0.49)^{\mathrm{a}}$ & $0.43(0.35)^{\mathrm{a}}$ & 0.41 & $4(1.44)$ \\
\hline Tyrosine & $0.15(0.24)$ & $0.20(0.23)$ & $0.27(0.28)$ & $0.20(0.60)$ & $0.26(0.62)$ & $0.49(0.56)^{\mathrm{b}}$ \\
\hline Phenylalanine & $0.18(0.26)$ & $0.09(0.14)$ & $0.21(0.24)$ & $0.28(0.17)^{\mathrm{e}}$ & $0.20(0.31)$ & $0.48(0.89)^{\mathrm{e}}$ \\
\hline Ornithine & $0.21(0.54)$ & $0.31(0.35)$ & $0.55(0.64)^{\mathrm{b}}$ & $0.48(0.27)^{\mathrm{a}}$ & $0.33(0.47)$ & $(1.33)^{\mathrm{e}}$ \\
\hline Lysir & $.68(0.96)$ & $0.62(0.71)$ & $1.26(1.42)^{\mathrm{a}}$ & $0.90(0.15)$ & $1.01(1.54)$ & $1.80(3.20)^{\mathrm{d}}$ \\
\hline Histidine & $12)$ & $0.04(0.13)^{\mathrm{a}}$ & $0.16(0.33)$ & $0.12(0.12)$ & $0.18(0.27)$ & $0.45(0.84)^{\mathrm{a}}$ \\
\hline $\begin{array}{l}\text { Total amino } \\
\text { acids }\end{array}$ & $4.44 \pm 1.60$ & $5.48 \pm 2.97$ & $8.50 \pm 3.63^{\mathrm{b}}$ & $10.80 \pm 1.89^{\mathrm{C}}$ & $10.42 \pm 4.88^{\mathrm{b}}$ & $13.82 \pm 7.63^{\mathrm{b}}$ \\
\hline $\mathrm{NH}_{3}$ & & $1.15 \pm 0.58^{b}$ & $0.90 \pm 0.20^{\mathrm{c}}$ & $1.14 \pm 0.59^{\mathrm{b}}$ & $1.50 \pm 0.77^{\mathrm{b}}$ & \\
\hline Molar ratio & $2.14 \pm 0.62$ & $2.87 \pm 1.04$ & $2.39 \pm 1.31$ & $3.06 \pm 0.99$ & $2.09 \pm 0.53$ & $1.24 \pm 0.36^{\mathrm{C}}$ \\
\hline
\end{tabular}

Values are the mean \pm s.D. or mean (range) of plasma concentrations of individual amino acids, taurine, ammonia, molar ratio and total amino acids expressed as $\mu$ moles per $\mathrm{ml}$ of the plasma.

${ }^{\mathrm{a}} p<0.1,{ }^{\mathrm{b}} p<0.05,{ }^{\mathrm{c}} p<0.01$ vs. control.

d $p<0.1$, e $p<0.05$ in Group 3 vs. control+Group $1+$ Group 2; or in Group 5 vs. control+Group 4.

Proline, citrulline, cystine, cysteine and arginine are omitted from the table as the values were small and variable.

TABLE 3. Amino acid analysis in the liver

\begin{tabular}{|c|c|c|c|c|c|c|}
\hline & $\begin{array}{c}\text { Control } \\
n=4\end{array}$ & $\underset{n=4}{\text { Group } 1}$ & $\begin{array}{c}\text { Group } 2 \\
n=6\end{array}$ & $\begin{array}{c}\text { Group } 3 \\
n=4\end{array}$ & $\begin{array}{c}\text { Group } 4 \\
n=4\end{array}$ & $\begin{array}{c}\text { Group } 5 \\
n=5\end{array}$ \\
\hline urine & $4.14(5.65)$ & $70(1.79)$ & $3.72(5.81)$ & $1.07(2.03)^{\mathrm{a}}$ & $4.32(5.20)$ & $4.08(6.57)$ \\
\hline $\begin{array}{l}\text { Aspartate+ } \\
\text { Asparagine }\end{array}$ & & & & & & \\
\hline Threonine & $0.26(0.96)$ & $39(3.40)^{\mathrm{b}}$ & $1.66(2.21)^{\mathrm{b}}$ & $0.25(0.80)^{\mathrm{d}}$ & $1.08(2.41)$ & $2.85(2.82)^{\mathrm{c}}$ \\
\hline & $.58(2.2$ & & & $0.30(1.1$ & & $3.06(3.5$ \\
\hline $\begin{array}{l}\text { mate } \\
\text { amine }\end{array}$ & $2.46(4.91)$ & )$^{a}$ & $3.93(9.40)$ & $0.71(1.6$ & 2.07 & $7.70(11$. \\
\hline tly & 1. $48(4.33)$ & & & 68 & $5.86(3.81)^{b}$ & $3.15(33.18)^{\mathrm{d}}$ \\
\hline & 6.86 & & 5. 6 & $23(4.5$ & 5.73 & $13.69(1$ \\
\hline & 2.28( & & & 531167 & & $3.08(3.76)$ \\
\hline & 0.46( & ( & 0. & $05=0$ & & $1.23(2.78)^{\mathrm{e}}$ \\
\hline & 1.04( & 8) & ( 1.79$)$ & $7 i^{-}$ & 0.84( & $1.52(1.80)$ \\
\hline & 49) & ( & 7) & )$^{b}$ & 1.82( & $3.31(4$. \\
\hline & 22) & & & & & 1. \\
\hline $\begin{array}{l}\text { Pher } \\
\text { als }\end{array}$ & $1.01(1.44)$ & $1.10(1.51)$ & $1.37(3.33)$ & $0.13(0.38)^{\mathrm{a}}$ & $0.76(0.39)$ & $1.29(1.01)$ \\
\hline & $3(1.41)$ & & $1.71(3.22)^{\mathrm{a}}$ & & & $2.36(2.52)^{b}$ \\
\hline & $1.76(2.52)$ & & $3.00(4.02)$ & $0.34(1.08)^{\mathrm{b}}$ & $1.75(2.50)$ & $3.86(4.05)^{\mathrm{a}}$ \\
\hline & $0.54(0.99)$ & & $0.45(0.39)$ & $0.03(0.07)^{\mathrm{a}}$ & $0.31(0.67)$ & $0.61(0.69)$ \\
\hline amino & $22.31(27.46)$ & $42.00(53.01)$ & $40.23(69.24)$ & $7.40(17.04)^{\mathrm{a}}$ & $24.19(15.18)$ & $58.31(76.94)^{\mathrm{a}}$ \\
\hline $\mathrm{NH}_{3}$ & $2.51(3.17)$ & $6.67(4.20)^{\circ}$ & $2.50(4.0)$ & $1.03(2.26)^{\mathrm{a}}$ & $3.67(9.1)$ & $4.65(7.59)$ \\
\hline
\end{tabular}

Values, mean (range), are expressed as $\mu$ moles per $\mathrm{g}$ of the liver. See legend for Table 2. 
TABLE 4. Survival rates of the animals after total (3/3) ischemia

$\begin{array}{cccccccc} & 1 & 2 & 3 & 4 & 5 & 6 & 7 \text { day } \\ \text { Control } & 11 / 11 & 11 / 11 & 11 / 11 & 11 / 11 & 11 / 11 & 11 / 11 & 11 / 11 \\ & (100.0) & (100.0) & (100.0) & (100.0) & (100.0) & (100.0) & (100.0) \\ 60 \mathrm{~min} & 10 / 17 & 6 / 17 & 6 / 17 & 6 / 17 & 6 / 17 & 6 / 17 & 6 / 17 \\ & (59) & (35) & (35) & (35) & (35) & (35) & (35) \\ 90 \mathrm{~min} & 6 / 11 & 6 / 11 & 5 / 11 & 3 / 11 & 3 / 11 & 3 / 11 & 3 / 11 \\ & (55) & (55) & (46) & (27) & (27) & (27) & (27) \\ 120 \mathrm{~min} & 4 / 12 & 4 / 12 & 4 / 12 & 3 / 12 & 3 / 12 & 3 / 12 & 3 / 12 \\ & (33) & (33) & (33) & (25) & (25) & (25) & (25)\end{array}$

The percentages are given in parentheses.

As the control, 3 animals underwent an ligation of the ilio-colic vessels (artery and vein), 3 animals did portal vein occlusion for $90 \mathrm{~min}$ with portal decompression and another 5 , a total temporary ischemia for $10 \mathrm{~min}$ with portal decompression.

See legend for Table 2.

In Group 5, glutamate+glutamine, glysine, alanine, methionine and tyrosine increased significantly and threonine, phenylalanine, ornithine and histidine showed an increasing trend. There existed, however, no elevations in the values of branched chain amino acids in either Group 5 or 4 . In Group 3, significant increases in glutamine + glutamate, glycine, alanine, valine and methionine were found, whereas increasing trends were noted in leucine, isoleucine, ornithine and phenylalanine. The molar ratio of branched chain amino acids (valine +leucine + isoleucine) to aromatic amino acids (phenylalanine-tyrosine) decreased significantly in Group 5, whereas no significant decrease was recognized in Group 1, 2 or 3 .

Survival rate of the animal. All the control animals survived more than one month. Deaths after ischemia mostly took place within $24 \mathrm{hr}$ after ischemia (Table 4). Relatively small survival rates were demonstrated also in the 60-90 min groups as well as in the 120 min group.

\section{Discussion}

In order to obtain reproducible ischemic liver damage, a special attention should be paid to make a complete occlusion of the blood flow into the liver. Validity of the complete occlusion of the blood flow was previously confirmed by Hirasawa et al. (1978) by a microsphere technique. Normaly sustained S-GOT and S-GPT levels prior to the revascularization showed the disappearance of blood flow between the liver and systemic circulation. Moreover, an injection of $1 \mathrm{ml}$ of india ink during ischemia in the present series caused no accumulation of india ink in the RES system of the liver.

According to Majno et al. (1960), death of the tissue has 4 steps: 1) A period of reversible alterations, 2) a point of no return, beyond which the cellular damage is irreversible (time of death), 3) a period of equilibration between the cell and its 
environment (pre-necrotic period), and 4) necrosis. In the present series, the pre-necrotic step was examined in the acute stage through a volume fraction of organelle disintegration with the aid of an assessment of amino acids in the liver and the serum enzyme levels. The organelle disintegration, assessed mainly by way of the volume ratio of autophagic vacuoles, may eventually express organelle equilibration, in which the intracellular materials are released from injured cells into surrounding environments (de Duve and Wattiaux 1966; Goldstein 1974). It started about $120 \mathrm{~min}$ after ischemia and the liver undergoing $120 \mathrm{~min}$ ischemia was followed by about $50 \%$ of frank necrosis of the liver in a later stage.

Of interest is the fact that the rise in total amino acids in the liver after ischemia for more than 120 min without reperfusion was in accordance with the elevated fraction of organelle disintegration. It is suggested that irreversible cellular damage occurred in $120 \mathrm{~min}$ after total ischemia. After 60 to $90 \mathrm{~min}$ ischemia, necrosis took place only in about $10 \%$ of hepatocytes in which irreversible cellular damage may have occurred within 60 to $90 \mathrm{~min}$.

In seven animals, necrotic fractions were estimated by postmortem examinations, and they confirmed the results of liver biopsy.

The survival rate of the animals never seemed to be parallel to the hepatocyte necrosis. Despite of only $10 \%$ necrosis, 65 to $75 \%$ of the animals died. Hirasawa et al. (1978) pointed out that irreversible cellular damage occurred between 90-120 min because no animal survived after $120 \mathrm{~min}$ of total ischemia. According to Farkouh et al. (1971) all dogs subjected to ischemia for more than 80 min died with a remarkable increase in lactate and depressions in high energy phosphate and respiration control ratio. The difference in the survival rate between these reports and the present series is not explained clearly. It is to be considered, however, that splenectomy performed in these experiments may have some influence on the survival rate.

Corresponding to the increased plasma values of amino acids a significant loss in amino acids in the liver after $120 \mathrm{~min}$ ischemia and $60 \mathrm{~min}$ reparfusion was noticed. The non-selective rise in various individual amino acids including branched chain amino acids and phenylalanine in the plasma after $120 \mathrm{~min}$ ischemia may be interpreted as the result from both washout from the liver and accumulation of amino acids that might be released from other tissues into the plasma. The decreasing trends in tyrosine and phenylalanine in the liver may also affect the values of the plasma. Plasma tyrosine showed, however, almost a normal value, which could be utilized in the liver during reperfusion in contrast to the branched chain amino acids that maintained higher levels. Thus, the molar ratio of the plasma after $120 \mathrm{~min}$ ischemia, in spite of possible washout of aromatic amino acids from the liver, may not be lowered because of the simultaneous washout of branched chain amino acids and the sequential catabolism of the aromatic amino acids.

The significant decrease in molar ratio after more than $120 \mathrm{~min}$ ischemia without reperfusion was due to the increased aromatic amino acids and unchanged 
branched chain amino acids. The elevated values in tyrosine and phenylalanine could be explicable as the result of incapable catabolism of the aromatic group on account of total loss of hepatic function during the complete ischemia. Branched chain amino acids, however, are predominantly metabolized in the muscle and kidney (Morgan et al. 1978). The loss of hepatic function during ischemia may not, therefore, affect their values. It could be seen that the lowered molar ratio is the result of the loss of liver function, which is consistent with the view that "lowering of this plasma ratio occurred solely as a result of liver damage" drawn by Morgan et al. (1978) in patients with various liver diseases.

It would be of interest to know the amino acid levels in the liver after ischemia without reperfusion. There were, however, increasing trends in both branched chain amino acids and aromatic amino acids together with various other individual amino acids. This is not surprising because the increases in 20 kinds of individual amino acids could be expected (Löffler et al. 1979).

The significant increase in plasma ammonia three times as high as the control value was found. The ammonia coma was caused in rats after an injection of $\mathrm{NH}_{4}$ $\mathrm{Cl}$ (Zieve et al. 1979), where an increase in ammonia more than ten times that in control animals was reported. The rise in ammonia level in this series may not have any major role in the animal death.

\section{Acknowledgment}

We express heartfelt gratitude to the Alexander von Humboldt-Stiftung for the support to this paper. Furthermore, this paper was carried out by kind cooperations of Dr. Gerhard Mall, Mr. Peter Rieger, Mrs. Margaret Kienle and Mrs. Zlata Antoni, Pathologisches Institut, Heidelberg, and Mr. Ulrich Stumpf, Biochemisches Institut, Heidelberg, West Germany.

\section{References}

1) de Duve, C. \& Wattiaux, R. (1966) Functions of lysosomes. Ann. Rev. Physiol.. 28, 435-492.

2) Farkouh, E., Danniel, A.M., Beaudoin, J-G. \& MacLean, L.D. (1971) Predictive values of liver biochemistry in acute hepatic ischemia. Surg. Gynec. Obstet., 132, 832-838.

3) Goldstein, I.M. (1974) Lysosomes and their relation to the cell in shock. The symposium on the cell in shock. Upjohn Company, 30-34.

4) Hirasawa, H., Chaudry, I.H. \& Baue, A.E. (1978) Improved hepatic function and survival with adenosine triphosphate-magnesium chloride after hepatic ischemia. Surgery. 83, 655-662.

5) Just, W., Salzer, M. \& Schimazeki, H. (1982) Amino acid levels in perfusion of rat liver in comparison to liver cell isolation. J. Cell Biol., in press.

6) Löffler, G. Petrides, P.E., Weiss, L. \& Harpaer, H.A. (1979) Physiologische Chemie, Springer-Verlag, Berlin-Heidelberg-New York, pp. 90.

7) Majno, G., LaGattua, M. \& Thompson, T.E. (1960) Cellular death and necrosis: chemical, physical and morphologic changes in rat liver. Virchows Arch. path. Anat., 333, 421-465.

8) Merz, W.E. (1974) Studies of the specific role of the subunits of choriogonadotropin for biological, immunological and physical properties of the hormone. Digestion and the $\alpha$-subunit with carboxypeptidase A. Europ. J. Biochem., 101, 541-553. 
9) Morgan, M.Y., Milson J.P. \& Scherlock, S. (1978) Plasma ratio of valine, leucine and isoleucine to phenylalanine and tyrosine in liver disease. Gut, 19, 1068-1073.

10) Müller, H.W., Scwulera, U., Salzer, M. \& Dose, K. (1979) Purification, subunit structure, and kinetics of the chloroform-released Fl ATPase complex from Rhodospirillum rubrum and its comparison with Fl ATPase forms isolated by other methods. Z. Naturforsch., 34c, 38-45.

11) Weibel, E.R. \& Elias, H. (1967) Introduction to stereologic principles. In: Quantitative Methods in Morphology, Springer-Verlag, Berlin-Heidelberg-New York, pp. 89-98.

12) Yamauchi, H., Koyama, K., Ouchi, K., Anezaki, T. \& Sato, T. (1976) Morphometric studies on the rat liver in biliary obstruction. Tohoku J. exp. Med., 119, 9-25.

13) Zieve, L., Doizaki, W.M. \& Derr, R.F. (1979) Reversal of ammonia coma in rats by L-dopa: a peripheral effect. Gut, 20, 28-32. 